\title{
Supporting the well-being of medical students
}

\section{Verna Yiu}

M

edical school has long been recognized as involving numerous stressors that can affect the wellbeing of students. ${ }^{1,2}$ In addition to coping with the normal stressors of everyday life, medical students must deal with stressors specific to medical school, which include information and input overload, financial indebtedness, lack of leisure time, and pressures of work, work relationships and career choices. ${ }^{1-3}$

Comparisons between medical students and other undergraduate student groups have shown a higher level of stress and depression among medical students. ${ }^{2,4}$ Moreover, the results of a study of 304 first- and second-year medical students revealed a $12 \%$ incidence of major depression and a lifetime prevalence of $15 \% ;^{5}$ the latter is 3 times higher than that of the average population. Other studies have reported incidences of depression among medical students in the range of $20 \%$ to $25 \%{ }^{5,6}$ Predictors of depression identified in these studies included previous depression or other mental health problems, perceived medical school stress, intensity and vulnerability traits, and a family history of depression. Being married or having a stable and supportive family were found to be protective factors. ${ }^{5-7}$

Reported levels of stress among medical students range anywhere from $25 \%$ to $75 \%{ }^{8,9}$ In the United States, a survey of 9 medical schools found that $47 \%$ of student respondents had at least 1 major issue related to mental health or substance use and that stress affected $26 \%$ within this group. ${ }^{9}$ What is equally disturbing in this study is that $70 \%$ of students indicated concerns about confidentiality and the potential impact of having stress-related issues appear on their academic record.

Medical students themselves tend toward certain characteristics that place them at increased risk of stress. A study at the University of Manitoba ${ }^{10}$ found that although medical students had high personal standards, which gave them an advantage on entry to a highly competitive profession, these standards were associated with maladaptive perfectionism leading to excessive concerns about academic performance. These characteristics were significantly correlated with baseline symptoms of neuroticism and were predictive of depression and feelings of hopelessness at follow-up.

Coping strategies have also been studied in medical students. ${ }^{11}$ Although no specific coping strategies have been identified as common to medical students, support from family and friends, exercise, recreational activities and spirituality are all reported to promote a greater sense of well- being. A study of 140 medical students at Hong Kong University found, not surprisingly, that optimism and a positive outlook had the strongest negative correlations with depression and anxiety. ${ }^{11}$

One of the difficulties with stress in medical school is that students tend not to seek help from the support services available to them. The results of a survey from the University of Pennsylvania showed that although $24 \%$ of their medical students identified themselves as being depressed, only $22 \%$ of this group accessed mental health services. ${ }^{12}$ Barriers to access included lack of time, fear of lack of confidentiality, stigma associated with use of mental health services, cost, fear of documentation in academic records and fear of unwanted intervention. These barriers do not appear to improve on graduation, since $35 \%$ of physicians in the United States do not have a regular source of health care. ${ }^{13}$

Numerous recommendations have arisen from student groups, medical school associations and student affairs offices to counter the stressors of medical training with the aim of improving student well-being. Reported interventions include personal stress management techniques, support groups, workshops and retreats, well-being committees and other psychosocial support. ${ }^{14,15}$ In the 1990 s, the UCLA medical school had a comprehensive program aimed at primary stress prevention that consisted of wellbeing seminars and support groups for different student populations, involving more than $75 \%$ of students. ${ }^{14}$

The Student Affairs Office at the University of Alberta opened in 1987 and has gradually expanded its services to include many recommended interventions, from first- and second-year student support groups to well-being seminars, financial seminars, support for a student well-being committee, drop-in hours with an open-door policy and an identified group of vested, trained faculty advisers and a well-established career counselling service. However, advisers were aware that they were unable to reach some students. In most instances those students were reluctant to come forward because of the stigma resulting from the perception that mental health problems arise from a lack of inner fortitude.

The suicide of a dental student at the University of Alberta in 2002 led to an internal review of the Student Affairs Office and its activities. We obviated the barriers to seeking help by instituting mandatory one-on-one meetings with advisers for all first-year medical students to ensure that all students met an adviser early in their under- 
graduate career. Making the meeting mandatory eliminated any stigma. Each adviser was given an assessment guide so that all interviews would follow a consistent format. All first-year medical students met with an adviser twice in an academic year, and each session averaged 15 minutes in duration.

At the year-end assessment, $13 \%$ of students were identified as having significant stressors and as being unlikely to have sought help voluntarily. Over $50 \%$ of the stressors were personal in nature, and the remainder involved academic, health, financial and career issues. The major aim of the appointments was for the advisers to maintain contact with the students. Some students required additional counselling or referral for specific services. Issues were successfully resolved for over $80 \%$ of the students identified as having significant stressors. Although there have been no studies to identify the proportion of students who will not access help, the advisers felt that identifying the $13 \%$ of students who required help but would not have come forth on their own made the program worthwhile. Evaluations by students and the advisers of the one-on-one mandated sessions were all positive, regardless of whether the student had any identified stressors. We are presently into our third year of the mandatory one-on-one sessions.

In conclusion, we need to continue to be attentive to the well-being of medical students, particularly in the face of new pressures of rising tuition costs and career matching. The challenges to all student affairs offices in Canadian medical schools are to promote student well-being and provide students with the coping tools to deal with stress throughout their undergraduate and postgraduate training and professional life. Addressing and maintaining one's mental health and well-being should become a lifelong focus for all medical students.

This article has been peer reviewed.

Verna Yiu is Assistant Dean, Student Affairs, at the Faculty of Medicine and Dentistry, University of Alberta.
Competing interests: None declared.

Acknowledgements: I would like to thank Ms. Marj Thomson, the Student Affairs Administrative Assistant at the Faculty of Medicine and Dentistry, University of Alberta, and our dedicated Student Advisors, who have helped in the development and implementation of our mandatory Student Advisor sessions.

\section{References}

1. Miller GD, Miller EC, Peck OC. Medical student needs assessment and student affairs programming. 7 Med Educ 1981;56:518-20.

2. Firth J. Levels and sources of stress in medical students. Br Med 7 1986;292: 1177-80.

3. Supe AN. A study of stress in medical students at Seth G.S. Medical College. 7 Postgrad Med 1998;44:1-6.

4. Stecker T. Well-being in an academic environment. Med Educ 2004;38:46578.

5. Tyssen R, Vaglum P, Gronvold NT, Ekeberg O. The impact of job stress and working conditions on mental health problems among junior house officers. A nationwide Norwegian prospective cohort study. Med Educ 2000;34:374-84.

6. Zoccolillo M, Murphy GE, Wetzel RD. Depression among medical students. 7 Affect Disord 1986;11:91-6.

7. Tyssen R, Vaglum P, Gronvold NT, Ekeberg O. Factors in medical school that predict $\mathrm{PG}$ mental health problems in need of treatment. A nationwide and longitudinal study. Med Educ 2000;35:110-20.

8. Mosley TH Jr, Perrin SG, Neral SM, Dubbert PM, Grothues CA, Pinto BM. Stress, coping and well-being among third year medical students. Acad Med 1994;69:765-7

9. Guthrie EA, Black D, Shaw CM, Hamilton J, Creed FH, Tomenson B. Embarking upon a medical career: psychological morbidity in first year medical students. Med Educ 1995;29:337-41.

10. Hays LR, Cheever TC, Patel P. Medical student suicide 1989-1994. Am 7 Psychiatry 1996;153:553-5.

11. Stern M, Norman S, Komm C. Medical students' differential use of coping strategies as a function of stressor type, year of training and gender. Bebav Med 1993;18:173-80.

12. Chew-Graham CA, Rogers A, Yassin N. "I wouldn't want it on my CV on their records": medical students' experiences of help-seeking for mental health problems. Med Educ 2004;37:878-80.

13. Gross CP, Mead LA, Ford DE, Klag MJ. Physician, heal thyself? Regular source of care and use of preventive health services among physicians. Arch Intern Med 2000;160:3209-14.

14. Weinstein HMA. Committee on well-being of medical students and housestaff. 7 Med Educ 1983;58:373.

15. Coombs RH, Perell K, Ruckh JM. Primary prevention of emotional impairment among medical trainees. Acad Med 1990;65:576-81.

Correspondence to: Dr. Verna Yiu, Faculty of Medicine and Dentistry, University of Alberta, Edmonton AB T6G 2R7; fax 780 407-2870; verna.yiu@ualberta.ca 